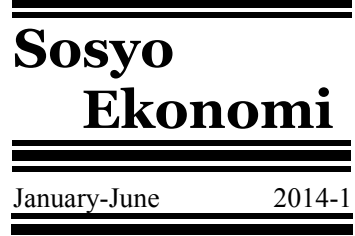

\title{
Türkiye'deki Hanehalklarının Haberleşme Talebinin Ampirik Analizi
}

\author{
Ahmet Burçin YERELİ \\ aby@hacettepe.edu.tr
}

Iş1l Fulya ORKUNOĞLU ŞAHIN

iforkunoglu@gazi.edu.tr

\section{An Empirical Analysis of Communication Demand by Households in Turkey}

\begin{abstract}
Communication is a basic need of human beings. For this reason, in this study, we want to obtain the communication expenditure is necessity or luxury good. So the ultimate goal is to assess the income (expenditure) elasticity and price elasticity of communication and it's budget share, also comparatively estimate the elasticity of demand in different expenditures in Turkey. Thus these elasticities have to give a conceivable picture of changing consumption of communication by the households in Turkey. After all, the article presents empirical analysis of demand of communication and other kind of expenditures in Turkey, for the period 2002-2009. At the research, ELES method was utilized. According to the results of analysis; throughout the Turkey, communication expenditures budget share is nearly $4 \%$, these expenditures income (expenditure) elasticity is less than 1 , price elasticity is $-1.06 \%$. Hence the demand of communication expenditure is acceptable as solid in the case of Turkey.
\end{abstract}

Keywords

JEL Classification Codes $\quad$ : C13, D12, L96. Turkey.
Communication Expenditures, Demand Analysis, ELES Method,

\section{Özet}

Haberleşme, insanın yaşamını sürdürmesindeki temel ihtiyaçlardandır. Bu çalışmada haberleşme harcamalarının, bireylerin toplam harcamalarındaki payı, gelir ve fiyat esnekliklerinin düzeyi sorgulanarak, bu harcama türünün zorunlu mal mı, yoksa talebi esnek türde mallardan mı olduğu açıklanmaya çalışılmaktadır. Araştırmada Türkiye'deki haberleşme harcamaları verileri olarak 2002-2009 yıllarına ilişkin TÜİK hanehalkı bütçe anketlerinden yararlanılmıştır. Buradan hareketle Türkiye'deki 12 farklı harcama türünün hanehalklarının bütçelerindeki payı, gelir (harcama) ve fiyat esneklikleri, haberleşme harcamaları ile karşılaştırmalı şekilde analiz edilmiştir. Bunun için regresyon analizi ile değişkenler arasındaki ilişkinin anlamlılığı ölçümlenmiştir. Bunu takiben bütçe payının, fiyat ve gelir (harcama) esnekliklerinin analizi için Genişletilmiş Doğrusal Harcama Sistemi (ELES) uygulanmıştır. Çalışmada yapılan analizler sonucunda; Türkiye genelinde haberleşme harcamalarının bütçe payı yaklaşık \%4, gelir (harcama) esnekliği 1'den küçük, fiyat esnekliği -1,06 olarak hesaplanmıştır. Bu nedenle haberleşme harcamaları, Türkiye örneği için, ihtiyaç malı olarak kabul edilebilir şeklinde yorumlanmıştır.

: Haberleşme Harcamaları, Talep Analizi, ELES Yöntemi, Türkiye. 


\section{Acknowledgement}

This paper is produced by Isil Fulya Orkunoglu Sahin's $\mathrm{PhD}$ dissertation which was under the supervision of Prof.Dr. Ahmet Burcin YERELI.

\section{Beyan}

Bu makale Dr. Işıl Fulya ORKUNOĞLU ŞAHIN'in Prof. Dr. Ahmet Burçin YERELİ danışmanlığında yürütülen doktora tezinden üretilmiştir. 


\section{Giriş}

Haberleşme, ulusal ve uluslararası hukuki belgelerle bireylere tanınmış kişisel hak ve hürriyetlerdendir. Haberleşme harcamaları denildiğinde ise hanehalkları tarafından haberleşme faaliyetlerinin gerçekleştirilmesinde katlanılan bedel ifade edilmektedir. Haberleşme harcamalarının bileşimi rakamsal olarak gelişmiş ve gelişmekte olan ülkelere göre farklılık gösterse de hanehalklarının temel ihtiyaçlarından olan haberleşme harcamalarının pek çok farklı gelişmişlik seviyesine sahip ülkede oransal açıdan birbirine benzer seyrettiği görülmektedir.

Türkiye'de haberleşme sektörünün yapısı incelendiğinde; haberleşme sektöründeki oligopolistik yapının sektörün üçlü saç ayağını oluşturan mobil hatta, sabit hatta ve internette devam ettiği, cep telefonu penetrasyon oranlarındaki yükselişe paralel şekilde sektörde faaliyet gösteren firmalar arasındaki rekabetin gittikçe şiddetlendiği, buna karşılık sabit hat kullanım oranlarının ülkemizde de tüm dünyada olduğu gibi günden güne düştüğü gözlemlenmektedir. $\mathrm{Bu}$ düşüşü dizginlemek için sabit hat operatörleri çeşitli kampanyalar düzenlemektedirler. Örneğin Türk Telekom, sabit hattını kapatarak yalın ADSL kullanımını tercih eden abonelerden aylık sabit hat kullanım bedeli amakta iken, sabit hat aboneliklerini kapattırmayan fiber internet abonelerinden yıllık sabit hat abonelik bedelini alınmamaktadır. Haberleşme sektörünün diğer ayağı olan internet kullanım aboneliklerinde ise ADSL ve fiber internet kullanım oranlarında artış gözlenmektedir. Dolayısıyla bu çalışma ile haberleşmenin günümüzde giderek artan öneminin, haberleşme harcamalarının talebine olan etkisi ölçülmek istenmiştir. $\mathrm{Bu}$ çalışmada haberleşme harcamalarının bütçedeki payı, gelir ve fiyat esneklikleri ile haberleşme talebi analiz edilmektedir.

Birinci bölümde ekonometrik modele, kullanılan verilere ve parametre tahminlerine ayrıntılı şekilde değinilirken, ikinci bölümde çalışma sonucunda elde edilen bulgular önceki çalışma sonuçları ile karşılaştırmalı şekilde sunulmaktadır. Üçüncü bölümde ise sonuç ve gelecek çalışmalar için önerilere yer verilmektedir.

\section{Genişletilmiş Doğrusal Harcama Sistemi (ELES)}

Literatürde talep analizi araştırmalarında yoğunlukla kullanılan yöntemler; 1954'te Stone'un geliştirdiği Doğrusal Harcama Sistemi - Linear Expenditure System (Sasaki \& Saegusa, 1974) ile harcama veya gelirin ikinci dereceden fonksiyonları olarak Pollak ve Wales (1979) ile Ryan ve Wales'in (1999) ilk kez uyguladıkları İkinci Dereceden Harcama Sistemi - Quadratic Expenditure System (Lyssiotou et al. 2001) ve 1980 yılında Deaton ve Muellbauer' in oluşturduğu Yaklaşık İdeal Talep Sistemi - Almost Ideal Demand System ve Genişletilmiş Doğrusal Harcama Sistemi - Extended Linear Expenditure System (Blanciforti \& Gren, 1983)'dir. 
Çalışmada kullanılan ELES yöntemi Lluch tarafindan 1973'te geliştirilmiştir. $\mathrm{Bu}$ yöntemde hanehalkının tüm mal ve hizmetlere yönelik harcamaları hesaplamalara dâhil edilmekte ve hanehalkının sınırlı bütçeye dayanan fonksiyonda fayda maksimizasyonu sağladığı kabul edilmektedir (Ulman, 2011). ELES, toplam harcamayı, kullanılabilir gelirle, marjinal tüketim eğilimini ise marjinal bütçe payı ile ikame etmektedir (Koutsoyiannis, 2004). Buna göre ELES eşitliği şöyledir (Lluch \& Williams, 1975):

$f(i)=q p_{t}=p_{t} \gamma+b_{t}\left(y-\Sigma p_{t} \gamma\right) \quad l=1,2,3 \ldots, n$

$f($ ()) i malı için talep fonksiyonu olup, (i) grup için yapılan harcamayı

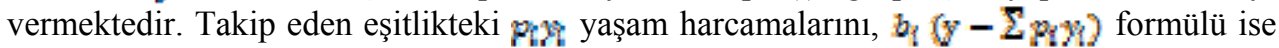
yaşamdışı harcamaları göstermektedir. 1. eşitlikte, $q_{i}$ hanehalklarının kişibaşına tükettikleri i malı miktarını, $y_{i} i$ malının minimum miktarını, $p_{i}$ i malının fiyatını, $h_{i}$ marjinal bütçe payını, $y$ tüketicinin toplam geliri olan hanehalklarının kişibaşına gelirini ifade etmektedir (Zhi-cheng et al., 2011).

Çalışmada kullanılan ELES yaklaşımında ilk olarak aşağıda verilen regresyon eşitliğindeki parametreler hesaplama kolaylığı nedeniyle uygulamada çoğunlukla EKK yöntemi ile tahmin edilmektedir (Shaukat, 1985). İkinci eşitlikte:

$\theta_{\mathrm{ith}}=\alpha_{h}+\beta_{\mathrm{h}} \gamma_{\mathrm{m}}+\boldsymbol{s}_{\mathrm{th}} h=1,2, \ldots ., 12, \mathrm{i}=1,2, \ldots ., 26$,

$i$ bireyleri, $t$ zamanı, $h$ harcama türlerini göstermektedir. Burada; $\theta_{\text {ith }} i$ 'inci bireyin $t$ zamanındaki $h$ harcama türüne yaptığ kişi başına (TL cinsinden) harcamadır. $Y_{\text {it }}$ $i$ 'inci bireyin t zamanındaki toplam (TL cinsinden) kişi başına harcamasıdır. $\pi_{h}$ ve $\beta_{k}$ h'ıncı harcama türü için sırasıyla sabit terim ve eğim katsayılarıdır. $z$ 'lar rastgele hata terimini ifade etmektedir. Panel veri setinde yer alan 234 verinin kullanılması ile elde edilen tahmin sonuçları her harcama türü için hesaplanmıştır.

\subsection{Veri}

Analizde yer alan harcama türleri 12 kategoriye ayrılmıştır. Bunlar sırasıyla (TÜIKK, 2011):

1. Gıda ve alkolsüz içecek harcamaları,

2. Alkollü içecekler, sigara ve tütün harcamaları,

3. Giyim ve ayakkabı harcamaları, 
4. Konut ve kira harcamaları,

5. Ev eşyası ve ev bakım hizmetleri harcamaları,

6. Sağlık harcamaları,

7. Ulaştırma harcamaları,

8. Haberleşme harcamaları,

9. Eğlence ve kültür harcamaları,

10. Eğitim hizmetleri harcamaları,

11. Lokanta ve otel harcamalar1,

12. Çeşitli mal ve hizmet harcamalarıdır.

Haberleşme harcamaları; posta hizmetlerinin, telefon ve telefaks ekipmanlarının ve hizmetlerinin harcamalarını ifade etmektedir (TÜIK, 2011).

Araştırmanın zaman boyutunda 2002-2009 dönemleri arasındaki 9 yıllık gözlemler yer alırken, yatay kesit boyutunda İstatistiki Bölge Sınıflandırması (IBBS) Düzey 2'deki 26 bölgeye ait gözlemler bulunmaktadır. Bu veriler TÜİK'ten edinilmiştir (TÜİK, 2012). Çalışmada kullanılan veri panel veridir. Panel veri kümesindeki toplam veri sayısı ise 234'tür.

\subsection{ELES'in Parametre Tahmini}

ELES metodu doğrusal regresyon analizinin bulguları ile 12 harcama türünün fiyat esnekliklerinin, gelir esnekliklerinin ve bütçe paylarının tahmininde kullanılmaktadır.

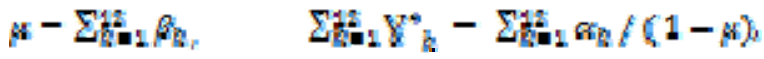

$$
\begin{aligned}
& y_{k}^{m}=a_{k}+\beta_{k} \sum Y_{k} \\
& \mu=\sum_{k=1}^{12} \beta_{k}
\end{aligned}
$$

Dördüncü eşitlikte, $\mu$ eğim katsayılarının toplamını ( $\beta$ )'yı ifade etmektedir. Bu işlemin sonucunda $\mu$ ile gösterilen 12 harcama türünün eğim katsayılarının toplamı olan ๑,PSร2 değeri elde edilmektedir. 
$\sum_{k=1}^{12} \gamma_{n}^{*}$

Beşinci eşitlikte sabit terim katsayılarının 12 harcama türü için toplam değeri -6.5207 olarak hesaplanmıştır.

$$
\gamma_{g}^{*}=x_{\mathrm{a}}+\beta_{\mathrm{a}} \Sigma Y_{\mathrm{k}}^{*}
$$

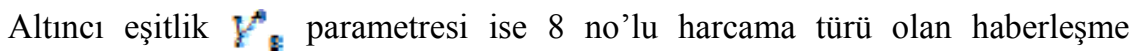
harcamaları için sabit terim katsayısında tahmin edilen değerin hesaplanmasında kullanılmaktadır. Esnekliklerin ve bütçe paylarının tahmin edilmelerine yardımcı olacak parametre tahminlerinin elde edilebilmesi için yukarıdaki denklemden 12 harcama türünden her birisi için sırasıyla ayrı ayrı hesaplama yapılmıştır.

h'ıncı harcama türünün bütçe payı:

$$
\beta_{\hbar}^{m}=\beta_{i} / \mu
$$

olup, bu eşitlik yardımıyla çalışmada ele alınan harcama türleri için bütçe payları hesaplanmıştır. Burada eğim katsayısı $\left(\beta_{h}\right)$ eğim katsayılarının toplamına $(\mu)$ bölünmektedir. Harcama türleri için bireylerin tasarruf etmedikleri, gelirlerinin tamamını tükettikleri ve toplam harcamaların hanehalklarının yaklaşık gelirlerini oluşturduğu varsayımı altında gelir (harcama) esneklikleri sekizinci eşitliğe göre hesaplanmıştır.

$$
\xi_{k}=\left(\beta_{k} / \mu\right) /\left(\mathrm{Y} / e_{h}\right)
$$

Burada Y yerine kişi başına toplam harcamaların ortalaması alınmıştır. Ayrıca $\theta_{\delta_{0}} h$ 'ıncı harcama türü için kişi başına ortalama harcama değeridir. Çalışmada kullanılan verilerden kişi başına toplam harcamalar için ortalama değer 1012.1 TL olarak bulunmuştur. Harcama türleri için ortalamalar; her bir harcama türü için sırasıyla:

$$
\theta_{1}=289.09 \mathrm{TL}, \theta_{2}=49.00 \mathrm{TL}, \theta_{3}=71.78 \mathrm{TL}, \theta_{4}=299.25 \mathrm{TL}, \theta_{5}=74,91 \mathrm{TL}, \theta_{\mathrm{s}}=
$$
$22.74 \mathrm{TL}, \theta_{7}=134.43 \mathrm{TL}, \theta_{\mathrm{g}}=49.50 \mathrm{TL}, \theta_{\mathrm{g}}=25.83 \mathrm{TL}, \theta_{10}=21.21 \mathrm{TL}, \theta_{11}=44.28 \mathrm{TL}$ ve $\theta_{12}=46.23 \mathrm{TL}$ olarak hesaplanmıştır. $\mathrm{h}$ 'ıncı harcama türünün fiyat esnekliği hesaplamasında ise dokuzuncu eşitlikteki formül kullanılmıştır. 


$$
\lambda_{k}=\left(1-\beta_{k}\right) /\left(\gamma_{k}^{*} / e_{h}\right)-1
$$

\subsection{Bulguların Değerlendirilmesi}

Araştırmada 12 harcama türü toplamının hanehalklarının gelirlerini oluşturduğu, bireylerin tasarruf etmedikleri, gelirlerinin tamamını tükettikleri varsayılıp hanehalklarının yaklaşık gelirleri elde edilmiştir. Çalışmada her bir harcama türü için sabit terim, gelir (eğim), $F$-istatistiği, $F$-istatistik olasılık değeri $(p)$ ve $R^{2}$ gibi değişkenler için katsayı tahminlerinde bulunulmuştur. Oluşturulan regresyon denkleminin analizinin başarısının ölçümünde t-itatistiğinden (Narayana \& Vani, 2000) ve $F$-istatistiğinden yararlanılmıştır.

Haberleşme harcamaları için regresyon analizi sonuçlarına göre Tablo: 1'de belirtildiği gibi f testi bütün olarak modelin anlamlılığını ifade etmektedir. Açıklanamayan değişkenlerin, açıklayıcı değişkenlere bölünmesi ile elde edilen değerdir. $p$ değerinin 0,00 olması modelin istatistiki olarak anlamlı olduğunu belirtmektedir. Regresyon denkleminin anlamlılık düzeyini ifade eden $\mathrm{R}^{2}$ katsayısının değerinin haberleşme hizmetinde 0,95 değeri ile 1'e yaklaşması modelin istatistikî olarak anlamlı olduğunu ifade etmektedir (Özer, 1985). Bu sonuç bireylerin tasarruf etmedikleri, gelirlerinin tamamını tükettikleri ve toplam harcamaların hanehalklarının yaklaşık gelirlerini oluşturduğu varsayımı altında haberleşme harcamalarındaki toplam değişimin \%95'inin kişi başına toplam gelir tarafından açıklandığını göstermektedir. Aynı varsayım altında eğim katsayısı tahmini 0,04 olup, bu sonuca göre diğer her şey sabitken kişi başına toplam gelir (harcama) $1 \mathrm{TL}$ arttığında, haberleşme harcamaları 0,04 TL artacaktır. Nitekim Tablo: 1'deki regresyon analizinin geneli incelendiğinde; en yüksek belirlilik katsayısı değerinin ( $\mathrm{R}^{2}$ katsayısı) $\% 0,95$ ile haberleşme harcamalarına ait olduğu görülmektedir. Analizde haberleşmeden sonra en yüksek belirlilik katsayısına sahip harcama türü \%91 değeri ile ulaştırmadır.

Tablo: 2'de Türkiye'deki hanehalklarının talep esnekliklerinin analizi görülmektedir. Araştırmada 12 harcama türü kategorisi için yapılan harcama toplamının hanehalklarının gelirlerini oluşturduğu; gelirlerin tamamının harcandığı; hanehalkının servetleri ve diğer yatırımlarının sabit kabul edildiği varsayımlarından hareketle gelir esnekliği yerine harcama esnekliği hesaplanması yoluna gidilmiştir. Gelirin tamamının tüketildiği varsayımı altında gelir esnekliği 1'in altında olan harcama türleri ihtiyaç malı olarak dikkate alınırken, 1'in üzerinde olanlar lüks mal olarak düşünülebilir. Ayrıca gelir esnekliği 0'a yaklaştıkça ilgili mala duyulan ihtiyaç düzeyi artar. Bu durumda gıda ve alkolsüz içecek harcamalarının gelir (harcama) esnekliği 0'a en yakın değere sahip olacağı için, çalışmada ele alınan harcama türleri arasında en fazla zorunlu harcama türünün gıda ve alkolsüz içecek harcamaları olduğunu görülmektedir. Buna karşın gelir (harcama) esnekliği en yüksek olan harcama türü 1,43 seviyesi ile ulaştırma olarak tespit edilmiştir. $\mathrm{Bu}$ durum ulaştırma harcamalarının lüks mal olarak değerlendirilmesi gerektiğine işaret 
etmektedir. Bunu izleyen diğer lüks kabul edilebilecek harcamalar; eğlence ve kültür, restaurant, otel ve eğitim harcamalarıdır (Sarntisart \& Warr, 2011). Ancak analiz sonuçlarına göre hanehalkı bütçesinde en yüksek orana sahip kira harcamaları ile çok daha düşük bir paya sahip haberleşme harcamaları neredeyse aynı fiyat ve gelir esnekliklerine sahiptirler. Dolayısıyla gelir (harcama) esnekliği 0,9456 olarak tahmin edilen haberleşme harcamaları da konut ve kira harcamaları gibi en temel ihtiyaçlardan olduklarından zorunlu mallar kategorisinde sayılabileceklerdir. Nitekim gelir esnekliği 1'den düşük olan harcama türlerinden gıda ve alkolsüz içecek harcamaları, giyim harcamaları, alkollü içecek harcamaları, sağlık harcamaları, mobilya harcamaları, haberleşme harcamaları, konut harcamaları ve çeşitli mal ve hizmet harcamaları düşük esneklik düzeyleri ile birer ihtiyaç malı kabul edilmişlerdir. Tablo: 2'de belirtilen gelir (harcama) esneklik değeri ile diğer her şey sabitken, toplam gelirdeki (harcama) \%1'lik artış haberleşme harcamalarını \%0,9456 artırmaktadır. 
Tablo: 1

\section{Regresyon Analizi Sonuçları}

\begin{tabular}{|c|c|c|c|c|c|c|c|c|}
\hline Harcama Türü & & Sabit Terim & Gelir & F-istatist. & $\begin{array}{l}\text { F-ist. Ol. } \\
\text { Değeri (p) }\end{array}$ & $\mathrm{R}^{2}$ & $\begin{array}{l}\text { Sabit Terim } \\
\text { St. Hata }\end{array}$ & $\begin{array}{l}\text { Gelir } \\
\text { St. Hata }\end{array}$ \\
\hline \multirow[t]{3}{*}{ Gida, A.İ. } & Katsayı & 111,5844 & 0,1504 & 83,7814 & 0,0000 & 0,2973 & 19,4792 & 0,0164 \\
\hline & $\mathrm{t}$ - istatist. & 5,7283 & 9,1532 & & & & & \\
\hline & Olasılık değeri & 0,0000 & 0,0000 & & & & & \\
\hline \multirow[t]{3}{*}{ Alkollü İç., T. } & Katsay 1 & $-2,6801$ & 0,0455 & 885,3822 & 0,0000 & 0,8172 & 0,8482 & 0,0007 \\
\hline & t- istatist. & $-3,1594$ & $-3,1594$ & & & & & \\
\hline & Ol. Değ. & 0,0018 & 0,0018 & & & & & \\
\hline \multirow[t]{3}{*}{ Giyim, A. } & Katsayı & 17,5848 & 0,0479 & 83,7814 & 0,0000 & 0,2973 & 2,3755 & 0,0020 \\
\hline & t- istatist. & 7,4023 & 23,9326 & & & & & \\
\hline & Olasılık değeri & 0,0000 & 0,0000 & & & & & \\
\hline \multirow[t]{3}{*}{ Konut, K. } & Katsayı & $-22,9761$ & 0,2784 & 1714,688 & 0,0000 & 0,8964 & 7,9710 & 0,0067 \\
\hline & t- istatist. & $-2,8824$ & 41,4088 & & & & & \\
\hline & Olasılık değeri & 0,0044 & 0,0000 & & & & & \\
\hline \multirow[t]{3}{*}{ Ev Eş., E.B. } & Katsay1 & 1,5547 & 0,0649 & 1642,135 & 0,0000 & 0,8923 & 1,8997 & 0,0016 \\
\hline & t- istatist. & 0,8183 & 40,5232 & & & & & \\
\hline & Olasılık değeri & 0,4141 & 0,0000 & & & & & \\
\hline \multirow[t]{3}{*}{ Sağlık } & Katsay1 & $-0,1294$ & 0,0196 & 372,6093 & 0,0000 & 0,6530 & 1,2045 & 0,0010 \\
\hline & t- istatist. & $-0,1074$ & 19,3030 & & & & & \\
\hline & Olasılık değeri & 0,9145 & 0,0000 & & & & & \\
\hline \multirow[t]{3}{*}{ Ulaştırma } & Katsay1 & $-78,1840$ & 0,1869 & 2240,7000 & 0,0000 & \begin{tabular}{|l|}
0.9188 \\
\end{tabular} & 4,6799 & 0,0039 \\
\hline & t- istatist. & $-16,7064$ & 47,3360 & & & & & \\
\hline & Olasılık değeri & 0,0000 & 0,0000 & & & & & \\
\hline \multirow[t]{3}{*}{ Haberleşme } & Katsay1 & $-2,6801$ & 0,0455 & 4053,014 & 0,0000 & 0,9534 & 0,8482 & 0,0007 \\
\hline & t- istatist. & $-3,1594$ & 63,6632 & & & & & \\
\hline & Olasılık değeri & 0,0018 & 0,0000 & & & & & \\
\hline \multirow[t]{3}{*}{ Eğlence, $\mathrm{K}$. } & Katsayı & $-10,2009$ & 0,0315 & 1221,114 & 0,0000 & 0,8604 & 1,0693 & 0,0009 \\
\hline & t- istatist. & $-9,5389$ & 34,9444 & & & & & \\
\hline & Olasılık değeri & 0,0000 & 0,0000 & & & & & \\
\hline \multirow[t]{3}{*}{ Eğitim } & Katsayı & $-6,6131$ & 0,0238 & 374,726 & 0,0000 & 0,6542 & 1,4619 & 0,0012 \\
\hline & t- istatist. & $-4,5234$ & 19,3578 & & & & & \\
\hline & Olasılık değeri & 0,0000 & 0,0000 & & & & & \\
\hline \multirow[t]{3}{*}{ Lokanta $\mathrm{O}$. } & Katsay1 & $-17,3765$ & 0,0528 & 622,5638 & 0,0000 & \begin{tabular}{|l|}
0,7587 \\
\end{tabular} & 2,5119 & 0,0021 \\
\hline & t- istatist. & $-6,9175$ & 24,9512 & & & & & \\
\hline & Olasılık değeri & 0,0000 & 0,0000 & & & & & \\
\hline \multirow[t]{3}{*}{ Çeşitli M.H. } & Katsayı & $-4,4322$ & 0,0444 & 605,8204 & 0,0000 & 0,7536 & 2,1388 & 0,0018 \\
\hline & t- istatist. & $-2,0722$ & 24,6134 & & & & & \\
\hline & Olasılık değeri & 0,0395 & 0,0000 & & & & & \\
\hline
\end{tabular}


Tablo: 2

Analiz Sonuçları

\begin{tabular}{|l|r|r|r|r|r|r|}
\hline Harcama Türü & $\begin{array}{c}\text { Sabit Terim } \\
(\alpha)\end{array}$ & $\begin{array}{c}\text { Ĕgim Katsayıs1 } \\
(\beta)\end{array}$ & \multicolumn{1}{c|}{$\begin{array}{c}\text { Ortalama } \\
\text { Harcama }\end{array}$} & $\begin{array}{c}\text { Bütçe } \\
\text { Payı }\end{array}$ & $\begin{array}{c}\text { Gelir } \\
\text { Esnekliği }\end{array}$ & $\begin{array}{c}\text { Fiyat } \\
\text { Esnekliği }\end{array}$ \\
\hline $\begin{array}{l}\text { Gıda, Alkolsüz } \\
\text { İç. }\end{array}$ & 111,5844 & 0,1504 & 289,09 & 0,1527 & 0,5345 & $-0,6784$ \\
\hline Alkollü İçecek & 5,3479 & 0,0386 & 49,00 & 0,0392 & 0,8089 & $-0,9058$ \\
\hline Giyim, Ayak. & 17,5848 & 0,0479 & 71,78 & 0,0487 & 0,6865 & $-0,7758$ \\
\hline Konut ve Kira & $-22,9761$ & 0,2784 & 299,25 & 0,2827 & 0,9560 & $-1,0649$ \\
\hline Ev Eşyası, E. & 1,5547 & 0,0649 & 74,91 & 0,0659 & 0,8907 & $-0,9921$ \\
\hline Sağlık & $-0,1294$ & 0,0196 & 22,74 & 0,0199 & 0,8862 & $-1,0176$ \\
\hline Ulaştırma & $-78,1839$ & 0,1868 & 134,43 & 0,1897 & 1,4283 & $-1,4890$ \\
\hline Haberleşme & $-2,6801$ & 0,0456 & 49,50 & 0,0462 & 0,9456 & $-1,0641$ \\
\hline Eğlence, Kültür & $-10,2009$ & 0,0315 & 25,83 & 0,0320 & 1,2539 & $-1,3993$ \\
\hline Ĕgitim & $-6,6131$ & 0,0239 & 21,21 & 0,0242 & 1,1565 & $-1,3199$ \\
\hline Lokanta, Otel & $-17,3765$ & 0,0528 & 44,28 & 0,0537 & 1,2268 & $-1,3877$ \\
\hline $\begin{array}{l}\text { Çeşitli mal ve } \\
\text { hizm. }\end{array}$ & $-4,4322$ & 0,0444 & 46,23 & 0,0451 & 0,9869 & $-1,1046$ \\
\hline Toplam & $-6,5207$ & 0,9852 & & & & \\
\hline
\end{tabular}

Çalışmada fiyat esneklikleri tüm harcama türleri için beklenen işarete sahiptir (Rea \& Lage, 1978). Tablo: 2'ye göre fiyat esnekliği en düşük olan harcama türü gıdadır. Fiyat esnekliği en yüksek olan harcama türü ise ulaştırma olarak belirlenmiştir. Fiyat esneklikleri mutlak değer olarak 1'in altında olan harcama türleri sırasıyla; gıda, giyim ve alkollü içecekler olarak tespit edilmiştir. Bu sonuç ilgili harcama türlerinde esnekliğin katı olduğunu ifade etmektedir. Fiyat esnekliği mutlak değer olarak 1'in üzerinde olan harcama türleri en büyük değerden başlamak üzere; ulaştırma, eğlence, lokanta, eğitim, çeşitli mal ve hizmetler, konut, haberleşme ve sağllk olarak tahmin edilmiştir. Bu durum ilgili harcama türlerinin fiyat esnekliklerinin yüksek olduğu anlamına gelmektedir. Buna karşın fiyat esneklikleri 1'e çok yakın olması nedeniyle; konut, haberleşme ve sağlık harcama türleri için esnekliklerin birim esnek olduğu da söylenebilir. Haberleşme harcama türü için fiyat esnekliği -1,0641 olarak tahmin edilmiştir. Esnekliğin 1'e oldukça yakın değer aldığ1 dikkati çekmektedir. Bu durum diğer her şey sabitken, haberleşme fiyatındaki \%1'lik artışın, haberleşme harcamalarını \%1,0641 azaltacağını göstermektedir.

Nitekim literatür incelendiğinde de ELES ile yapılan talep analizlerinin çoğunun, çalışmamızda olduğu gibi Engel Eğrilerini doğruladığı görülmektedir. Pek çok çalışmada kira, ulaşım ve eğlence harcamaları gibi harcamaların gelir esnekliği genellikle diğer harcama türlerinden daha yüksek bulunmuştur. Ancak gıda harcamalarının ve giyim harcamalarının gelir esnekliği, tüm harcama kategorileri içinde genellikle en düşük düzeyde bulunmuşlardır. Sonuçta hanehalklarının tüketim düzeylerindeki artışın en önemli ilk nedeninin gelirlerindeki artış, ikinci en önemli nedenin ise fiyatlarındaki değişim olduğu savunulmuştur (Bin \& Renjing, 2012). Ancak literatürde tüketim talebinin 
uluslararası karşılaştırmalı analizlerine kapsamlı bir şekilde yer veren çalışmalara, Lluch ve Williams’ın (1975) çalışmalarının haricinde, pek sık rastlanılmamaktadır. Bu çalışma 14 ülkeyi içermektedir. Araştırmadaki tüketim kategorileri gıda, ulaşım, eğlence, kira ve ev için katlanılan diğer harcamalar, kişisel bakım harcamaları ile giyimdir. Kullanılan yöntem ELES’tir. Gıda harcama türünün, kişinin gelirinde bir artış olduğunda fiyat esnekliği azalan tek harcama türü olduğunu iddia etmişlerdir. Diğer yandan çalışma sonuçlarının verildiği Tablo: 2'ye göre en çok ihtiyaç duyulan harcama türleri sırasıyla konut ve kira harcamaları, gıda ve alkolsüz içecek harcamaları, ulaştırma, mobilya, giyim ve ayakkabı ile haberleşme harcamalarıdır. Ortalama konut ve kira harcaması 299 TL, gıda harcaması $289 \mathrm{TL}$, ulaştırma harcaması $134 \mathrm{TL}$, giyim ve ayakkabı harcaması yaklaşık 72 TL iken, hanehalklarının aylık ortalama haberleşme harcaması 49 TL'dir. Harcama türlerinin bütçe payları incelendiğinde; en yüksek bütçe payını \%28,27 değeri ile konut, $\% 18,97$ ile ulaştırma ve \%15,27 ile gıda harcamalarının izlediği görülmektedir. En düşük bütçe paylarına sahip harcamalar sırası ile \%1,99 değeri ile sağlı harcamaları, \%2,42 ile eğitim ve \%3,20 ile eğlence harcamalarıdır. Çalışmada ele alınan temel harcama türü olan haberleşmenin bütçe payı $\% 4,62$ 'dir.

Haberleşme harcamalarının aylık gelirdeki payının hesaplanmasında dikkate alınan haberleşme harcama türleri ülkemizde de OECD'deki gibidir. Şöyle ki haberleşme harcamalarının kapsamında; posta hizmetleri, telefon ve telefaks ekipmanları ve hizmetleri bulunmaktadır. Ancak hanehalklarının haberleşme harcamalarının fiyat ve gelir esneklikleri ile ilgili uluslararası literatürde hâlihazırda herhangi bir çalışmaya ulaşılamadığından, Tablo: 3'te yalnızca haberleşme harcamalarının aylık gelirdeki payı değişkeni ekseninde bir uluslararası karşılaştırma yapılabilmiştir.

Tablo: 3

Bazı OECD Ülkelerinde Haberleşme Harcamalarının Aylık Gelirdeki Payı (\%)

\begin{tabular}{|l|c|l|c|}
\hline Ülkeler & $\begin{array}{c}\text { Haberleşme } \\
\text { Harcamaları }\end{array}$ & Ülkeler & $\begin{array}{c}\text { Haberleşme } \\
\text { Harcamaları }\end{array}$ \\
\hline Lüksemburg & 1,78 & İspanya & 2,79 \\
\hline Danimarka & 1,82 & Almanya & 2,83 \\
\hline İngiltere & 2,16 & Polonya & 3,03 \\
\hline Finlandiya & 2,24 & Slovenya & 3,17 \\
\hline Kanada & 2,34 & İsveç & 3,24 \\
\hline Avusturya & 2,40 & İrlanda & 3,43 \\
\hline Belçika & 2,40 & Çek Cum. & 3,56 \\
\hline Amerika & 2,41 & Macaristan & 3,73 \\
\hline İtalya & 2,50 & Slovak C. & 3,76 \\
\hline Avustralya & 2,53 & Hollanda & 4,19 \\
\hline Portekiz & 2,62 & İsrail & 4,38 \\
\hline İzlanda & 2,65 & Kore & 4,39 \\
\hline Fransa & 2,68 & Meksika & 4,57 \\
\hline OECD 28 & 2,69 & Türkiye & 4,62 \\
\hline Norveç & 2,71 & & \\
\hline
\end{tabular}


Haberleşme harcamalarının aylık gelirdeki payı Tablo: 2'deki bütçe payı sütununda ve Tablo: 3'te görüleceği üzere Türkiye için \%4,62'dir. Bazı OECD ülkelerindeki haberleşme harcamalarının aylık gelirdeki payı ile karşılaştırıldığında bu değerin, OECD 28 ortalaması olan \%2,69'u aştığı görülmektedir. Nitekim Tablo: 3'te en yüksek değere sahip ülke olan Meksika'daki \%4,57 değerini, Kore'deki \%4,39 oranı izlemektedir. Aylık gelirdeki payına göre en düşük oranda haberleşme harcamalarına sahip ülkeler ise; \%1,78 ile Lüksemburg, \%1,86 ile Danimarka ve \%2,16 ile İngiltere'dir.

\section{Genel Değerlendirme ve Sonuç}

Haberleşme sektörü ekonomideki tüm sektörlerin gelişimine sağladığı katkı bakımından dikkate değerdir. $\mathrm{Bu}$ nedenle bu çalışmada hanehalkı tüketiminde haberleşmenin fiyat ve gelir (harcama) esnekliklerinin analizi yoluna gidilmiştir. Yapılan araştırmada 2002-2009 yılları Hanehalkı Bütçe Anketleri ile 26 bölgeyi içeren dokuz dönemin yatay kesit verileri ve zaman serilerinden oluşan panel veri seti ve Eviews-6 paket programı kullanılmıştır. Talep analizinde parametreler Genişletilmiş Doğrusal Harcama Sistemi ile tahmin edilmiştir. Türkiye için ELES'in parametre değerlerinden elde edilen katsayılar, istatistikî olarak anlamlı bulunmuşlardır.

Çalışmanın gelir (harcama) esneklik sonuçları Engel Yasası'na uygundur. Çalışmadaki tüm fiyat esnekliklerinin değeri temel talep fonksiyonuna uymakta olup, negatiftir. Talep esnekliği katı olan malların fiyatlarındaki artışların, tüketicilerin harcamalarını artırdığı, talebi esnek olan malların fiyatlarındaki artışların toplam harcamaları azaltacağı, birim esnek malların fiyatlarındaki artışların kaydadeğer oranda değişmeyecekleri söylenebilir. Çalışma sonucunda edinilen bulgular şöyledir: Harcama türlerinin ortalama harcamalardaki payına göre sırasıyla en yüksek paya konut ve kira harcamaları (299,25 TL), gıda ve alkolsüz içecek harcamaları (289 TL) ve ulaştırma harcamaları $(134,43$ TL) sahiptir. Dolayısıyla en yüksek bütçe payları bu üç harcama türüne aittir. Buna göre, konut ve kira harcamalarının oranı $\% 28$, ulaştırma harcamalarının oranı $\% 18$ ve gıda ve alkolsüz içecek harcamalarının oranı $\% 15$ tir. Türkiye genelinde haberleşme harcamalarının bütçe payı ise $\% 4$ civarındadır.

Çalışmadaki harcama türlerinin gelir (harcama) esneklikleri değerlendirildiğinde; incelenen harcama türlerinden esneklikleri 1'den küçük olan harcamalar arasında gıda, giyim, alkollü içecek, sağlık, ev eşyalarını takiben haberleşme harcamaları gelmektedir ki sözü edilen harcamalar zorunlu harcamalar olarak değerlendirilebilirler. Diğer harcama türleri ise esneklikleri 1'den büyük olup, lüks mal kategorisinde sayılabilirler.

Ancak çalışmadaki kısıt gelir verileri ayrıştırılmış şekilde edinilemediğinden, gelir (harcama) esnekliği hesaplamasında geliri harcamalar toplamının oluşturduğu, gelirin 
tasarrufa ya da yatırıma ayrılmayıp tamamının tüketildiği varsayımında bulunulmuş olmasıdır. $\mathrm{Bu}$ nedenle sonraki çalışmalarda kullanılabilecek değişkenlerin sayısı artırılabilir. Bunlar arasında; hanehalkı büyüklüğü, hanehalklarının gelirleri, tasarruf eğilimleri, alt harcama türlerinin aylık gelirdeki payları ya da tutarları vb. değişkenler sayılabilir. Bu değişkenlerin varlığı, haberleşme ürünlerinin posta hizmetleri, telefon ve telefaks hizmetleri, telefon ve telefaks bakım hizmetleri, internet hizmetleri vb. gibi haberleşme sektörünün alt segmentleri üzerine analizler düzenlenmesi ile daha ayrıntılı talep analizlerinin yapılabilmesi bakımından yararlı olacaktır. Bununla birlikte çalışmada 9 yıllık veri seti kullanılmıştır. Oysaki edinilebilmesi durumunda daha uzun vadeli verileri içerecek çalışmaların gözlem sayısı çokluğu sayesinde her bölge için ayrı ayrı harcama türlerinin alt ürün türleri bağlamında gelir ve fiyat esneklik analizlerine imkân sağlaması mümkün olacaktır.

Diğer yandan araştırma kapsamında talep analizinde önemli olan bir başka unsur harcama türlerinin fiyat esnekliklerinin değerlendirilmesidir. Dolayısıyla çalışmada fiyat esnekliği en yüksek olan lüks harcama türleri sırasıyla ulaştırma harcamaları, eğlence ve kültür harcamaları, lokanta ve otel harcamaları ile eğitim harcamalarıdır. Fiyat esnekliği birim esnek kabul edilebilecek harcama türleri konut, sağlık ve haberleşmedir. Gıda, giyim gibi harcama türlerinin fiyat esnekliği ise katı esnektir. Haberleşmenin fiyat esnekliği 1,06'dır. Bu durum haberleşme fiyatlarında yapılacak \%1'lik artışın, haberleşmeye dönük harcamalarda \%1,06 azalışa neden olacağını ifade etmektedir. Dolayısıyla haberleşme harcamalarındaki vergi artışına bağlı fiyat artışları, ilgili harcamaların hâsılalarında büyük bir değişim meydana getirmeyeceğinden, bu harcamaların yüksek oranda vergilendirilmesinin etkin bir maliye politikası olmayacağı düşünülmektedir. Ancak ülkemizde haberleşme üzerindeki vergilerin, kamu gelir politikalarının önemli araçlarından biri haline geldiği görülmektedir. Haberleşme harcamalarının aylık gelirdeki payı, Türkiye'de birçok OECD ülkesindekinden yüksektir. Ülkemizde haberleşme hizmetleri üzerindeki vergi oranları ise, dünya çapında uygulanan en yüksek vergi oranlarındandır. Bunun için sektör üzerinde büyük bir yük olan ve diğer ülkelerin çoğunda uygulanmayan Özel İletişim Vergisi ülkemizde de kaldırılmalı ya da bu verginin oranı aşamalı şekilde indirilmelidir. Sonuçta sektöre yönelik olarak uygulanacak yüksek vergi oranları bireylerin ve firmaların haberleşme hizmetini kullanım miktarlarını sınırlandıracak, bireylerin haberleşme hürriyetlerini engelleyecektir. Hâlbuki haberleşme harcamaları üzerindeki bir vergi indirimi, kısa vadede vergi hâsılatını düşürse de, uzun vadede sektörün ve kamu gelirlerinin yararınadır. Vergi indirimi ile fiyatı düşen hizmetlere olan talepteki artışla sektörde hizmet veren kurumlardan elde edilecek gelir artışı, vergi indirimi dolayısıyla kaybedilmiş olan gelirleri telafi edebilecektir. Bu durum ise telekomünikasyon pazarının gelişmesine, sektöre yerli ve yabancı sermayenin çekilmesine ve yeni şirketlerin girmelerine yardımcı olacaktır. Bunun aksine haberleşme harcamaları için fiyat artışlarına dayanarak yapılacak vergi artışlarının, bu harcamalar üzerinden elde edilecek vergi gelirlerinde büyük bir değişikliğe neden olmayacağından ötürü etkin bir maliye politikası olmayacağı düşünülmektedir. Ancak Türkiye'de haberleşme harcamaları üzerinden alınan 
yüksek oranlı vergiler, vergilendirmenin önemli bir aracı konumundadır. Nitekim ülkemizde haberleşme harcamalarının aylık gelirdeki payı pek çok OECD ülkesindeki paydan daha yüksektir. Bununla birlikte Türkiye haberleşme hizmetleri üzerindeki vergi oranlarının da dünyada en yüksek olduğu ülkelerden biridir. Özellikle özel iletişim vergisi çoğu ülkede uygulanmamakta ya da düşük oranlarda uygulanmakta iken, Türkiye'de oldukça yüksek oranda uygulanmaktadır.

Ancak cep telefonları üzerindeki özel iletişim vergisinde yapılacak bir indirimin olası etkileri hakkında yapılan bir çalışmaya göre; vergi oranının yüksekliği nedeniyle Türkiye'deki vergi gelirlerini diğer ülkelerin vergi gelirlerindeki düşüşten daha kötü etkileyebileceği ileri sürülmüş (Bagdadioğlu \& Çetinkaya,2008) olmasına rağmen, haberleşme vergilerindeki bir indirimin haberleşme hizmetlerinin kullanım miktarını artırarak, yerel ekonominin gelişmesine katkı sağlayacağı (Oğuz, 2013) da savunulmaktadır.

Özetle, çalışmada 9 yıllık veri seti kullanılmış olup, mümkünse ilerleyen çalışmalarda uzun süreli, daha fazla veri içeren ve haberleşme hizmetlerinin posta hizmetleri, telefon hizmetleri ve telefaks hizmetleri gibi alt kategorilerdeki değerlerinin de izlenebildiği; değişkenler arasına hanehalklarının harcama trendleri, hanehalkını oluşturan bireylerin sayısı, gelirleri ve tasarruflarının eklenebileceği ayrıntılı talep analizleri yapılabilmesi açısından oldukça yararlı olacaktır.

\section{Kaynakça}

Bağdadioğlu, N. \& M. Çetinkaya (2008), “Türk Mobil Telekom Sektörünün Vergilendirilmesinde Vergi Yükü Analizi ve Olası Bir Vergi İndiriminin Etkileri”, Yaklaşım, 16, 28-32.

Bin, X. \& X. Renjing (2012), "An Emprical Analysis on the Consumption Structure of Town Residents, Jiangxi province-based on the extended linear expenditure", International Conference on Applied Physics and Industrial Engineering, Physics Procedia, 24, 66066.

Blanciforti, L. \& R. Gren (1983), "An almost Ideal Demand System Incorporating Habits: An Analysis of Expenditures on Food and Aggregate Commodity Groups", The Review of Economics and Statistics, 65, 511-15.

Koutsoyiannis, A. (2004), Modern Macro Economic Models Assumptions, Çev. Muzaffer Sarımeşeli, Gazi Press, Ankara.

Lluch, C. \& R. Williams (1975), "Cross Country Demand and Savings Patterns: An Application of the Extended Linear Expenditure System", Review of Economics \& Statistics, 57, 32028. 
Lyssiotou, P. \& P. Pashardes \& T. Stengos et al. (2001), "Nesting Quadratic Logarithmic Demand Systems", Economic Papers, University of Cyprus, 1-11,

$<$ http://papers.econ.ucy.ac.cy/RePEc/papers/0201.pdf>, 23 April 2013.

Narayana, N.S. \& B.P. Vani (2000), "Earnings and Consumption by Indian Rural Laborers: Analysis with An Extended Linear Expenditure System”, Journal of Policy Modelling, 22, 256-65.

Oğuz, F. (2013), "Universal Service in Turkey: Recent Developments and A Critical Assessment”, Telecommunication Policy, 37, 13-23.

Özer, D.J. (1985), “Correlation and The Coefficient of Determination”, Psychological Bulletin, 97, 307-15, <http://mres.gmu.edu/pmwiki/uploads/Main/Ozer1985.pdf>, 20 April 2013.

OECD (2011), Communications Outlook 2011, <http://dx.doi.org/10.1787/88932396390>, 17 April 2013.

Rea, J.D. \& G.M. Lage (1978), "Estimates of Demand Elasticities For International Telecommunications Services", The Journal of Industrial Economics, 26, 363-81.

Sasaki, K. \& Y. Saegusa (1974), "Food Demand Matrix in An Approximate Linear Expenditure System”, American Journal of Agricultural Economics, 56, 263-70.

Sarntisart, I. \& P. Warr (2011), "Estimation of Consumer Demand System", Crawford School of Public Policy Lecture Notes, 1-40, $<$ http://www.crawford.anu.edu.au/acde/prc/pdf/Paper_G1.pdf>, 25 April 2013.

Shaukat, A. (1985), "Household Consumption and Savings Behavior in Pakistan: An Application of the Extended Linear Expenditure System”, The Pakistan Development Review, 24, 23-37.

TÜİK (2011), Hanehalkı Bütçe Araştırması 2009, Publication Number: 3582, June, XXI-XXIII, Ankara.

TÜİK (2012), Hanehalkı Bütçe Araştırması Tüketim Harcamaları Mikro Veri Setleri 2002-2009, Ankara.

Ulman, P. (2011), “Equivalence Scale in Terms of Polish Households' Source of Income”, Folia Economica Stetinensia, 10, 114-27, <http://www.degruyter.com/dg/viewarticle.../contentUri?t:ac...2012>, 25 April 2013.

Zhi-cheng, H. \& L. Xiao-xiang \& L. Zhi-xia et al. (2011), "Comparison Among The Consumption Structures of Different Income Groups of Urban Residents in Guanxi Based on Eles Model", Asian Agricultural Research, 3, 34-36. 
Ahmet Burçin YERELİ \& Iş11 Fulya ORKUNOĞLU ŞAHIN 